\title{
The Perspective of Acquired Immunity to Combat against Infectious Diseases: An Overview
}

\author{
Md. Shahidul Islam', Irfan Chaudhuri', Mahadee Al Mobin', Mobashara Islam³, \\ Md. Shahriar Mahmud ${ }^{4}$, Md. KutubUddin'1, K. M. Ariful Kabir ${ }^{5}$, Md. Kamrujjaman 1,6* \\ ${ }^{1}$ Department of Mathematics, University of Dhaka, Dhaka, Bangladesh \\ ${ }^{2}$ Department of Chemistry, Colby College, Maine, USA \\ ${ }^{3}$ Department of Genetic Engineering and Biotechnology, University of Dhaka, Dhaka, Bangladesh \\ ${ }^{4}$ Department of Computer Science \& Engineering, State University of Bangladesh, Dhaka, Bangladesh \\ ${ }^{5}$ Department of Mathematics, Bangladesh University of Engineering and Technology, Dhaka, Bangladesh \\ ${ }^{6}$ Department of Mathematics and Statistics, University of Calgary, Calgary, Canada \\ Email: ^kamrujjaman@du.ac.bd
}

How to cite this paper: Islam, Md.S., Chaudhuri, I., Al Mobin, M., Islam, M., Mahmud, Md.S., KutubUddin, Md., Kabir, K.M.A. and Kamrujjaman, Md. (2021) The Perspective of Acquired Immunity to Combat against Infectious Diseases: An Overview. Health, 13, 1020-1044.

https://doi.org/10.4236/health.2021.139077

Received: August 13, 2021

Accepted: September 15, 2021

Published: September 18, 2021

Copyright $\odot 2021$ by author(s) and Scientific Research Publishing Inc. This work is licensed under the Creative Commons Attribution International License (CC BY 4.0).

http://creativecommons.org/licenses/by/4.0/

\begin{abstract}
There is a long ritual of acquired immunity using physical exercise, a balanced diet, and pharmaceutical medication to generate immunity against a particular disease insight into the human body. This paper has extensively reviewed the impact of exercise, daily life practice, food selection, and several other issues to improve the immune system that combat infection. Studying the effect of exercise in varying degrees on the immunity system of humans is well developed and exhibit in this study. It investigates the prevention of pandemics due to herd immunity and finds the perfect amount of exercise to boost immunity to its maximum. Besides the life practice, it is also explored that vaccination can improve and optimize herd immunity.
\end{abstract}

\section{Keywords}

Natural Immunity, Medicated Immunity, Physical Exercise, Vaccination, Infectious Diseases

\section{Introduction}

December 2019, the planet had been experienced the COVID-19 pandemic, and therefore the development of a safe and reliable vaccination was urgent at that critical time [1]. Until August 13, 2021, the COVID-19 pandemic has caused nearly 4,347,996 deaths and has been 206,234,061 confirmed cases across the 
world [2]. Almost half of the records of deaths go unreported, as most countries only record people admitted in hospitals with confirmed infection [3].

The sole hope is that we have to remain alert and depend upon our immunity system if we want to survive with a healthy life because there is no other alternative except vaccination. A British study published in The Lancet medical journal looked at levels of neutralizing antibodies produced in vaccinated people exposed to the Delta, Alpha, and Beta variants [4]. A scientific, clinical, and epidemiological studies show the impact of physical exercise on the immune system [5], but no significant mathematical studies show the effects of physical activity [6]. The physical body is usually at war with outside threats like viruses, bacteria, fungi, toxins, and parasites. Despite this chaotic state, our body remains healthy most of the time by defeating viruses because of a robust immune system that can be boosted by physical exercise [7].

According to $\mathrm{CDC}$, more than five million Americans have missed their second doses of the Pfizer/Moderna COVID-19 vaccines [8] [9]. From almost $8 \%$ of those who got the first shot, some people are feared the side effects, such as flu-like symptoms, while others said that they felt a single shot was enough protection against the virus. In other cases, vaccine providers were forced to cancel second-dose appointments because they did not have enough supply [10].

The COVID-19 pandemic creates unprecedented health and social challenges with severe mental illnesses uniquely high risk for vulnerable populations [11]-[18]. In this work, we discussed that physical activity could reduce the severity of infection, significantly COVID-19 [19]-[26], extend insulin sensitivity, and reduce insulin levels [27]. High insulin levels are linked to inflammation, heart condition, diabetes, and cancer [22]. High blood pressure, diabetics, and cancer patients are vulnerable to COVID [28] [29] [30].

Stress can wreak havoc in our immune system, even eating right, sleeping enough, not smoking, or drinking, which reduces the body's ability to beat infections. An excessive amount of stress can hamper immunity, and when stress lasts for an extended time, it can put in danger with serious health issues, like depression or anxiety. Even chronic skin issues [31]-[37], so we have to try some stress management techniques to tackle it [27] [38].

Yoga can play an essential role in preventing and managing any disease like coronavirus by enhancing the immune system, which is also very helpful for depression, anxiety, and stress management [39]. When the immunity is robust regardless of what infection it is, whether bacterial or viral, it will remain healthy and guarded [40]-[54].

Harvard researcher Sara Lazar found that 40 - 50 years old meditators have critical brain structures almost like those of non-meditators of 20 years old young men. It improves focus, problem-solving power and emotional regulation, and survival instincts [55] [56]. If anyone is doing physical activities, especially yoga, breathing exercise, or meditation, they will reduce the health risks [57]-[70].

In this work, we discussed the physical activity that can reduce the infection of COVID-19 [71]. Physical activities extend insulin sensitivity and reduce insulin 
levels, including aerobics, strength training, and endurance exercise [72]. The combination of aerobic exercise training and resistance exercise (REX) may be more effective than either exercise mode alone. A significant advantage of exercise is its ability to scale back insulin levels and increase insulin sensitivity [30] [73] [74] [75]. Insulin may be a hormone that has several functions, allowing cells to require up sugar and amino acids from the bloodstream, which are then used for energy and maintaining muscle. High insulin levels are linked to inflammation, heart condition, diabetes, and cancer [76] [77]. High blood pressure, diabetics, and cancer patients are vulnerable to COVID. If people are doing physical activities, yoga or breathing exercises will reduce the risk [19].

We show that stress can wreak havoc in our system, even eating right, sleeping enough, not smoking or drinking, which reduces the body's ability to beat infections. Stressing an excessive amount of over something can hamper immunity and health [78] [79]. So, if someone discovers constantly stressed, they want to try some stress management techniques to tackle it. When stress lasts for an extended time, it can put the patient in danger for a few pretty severe health issues, like high vital signs, depression or anxiety, and even chronic skin issues [80].

Physical activity is regarded as one of the most important aspects of a healthy lifestyle [81]. A possible advantage of physical exercise in lowering communicable diseases, particularly viral pathologies, has been postulated [82], in addition to functions linked to the control of excess body weight, systemic inflammation, and chronic non-communicable diseases. Physical activity, both acute and chronic, significantly impacts the immune system [83] [84]. According to studies, the immunological response to exercise is modulated by characteristics such as regularity, intensity, duration, and type of effort applied [82] [85]. Moderate-intensity physical activities enhance cellular immunity, whereas extended or high-intensity workouts without adequate rest reduce cellular immunity, making people more susceptible to infectious diseases [83] [84]. The immunological decline happens after 90 minutes of moderate- to high-intensity physical activity, according to the International Society for Exercise and Immunology (ISEI) [86].

Increased immune vigilance and improved immune competence, which aid in pathogen control, are two benefits of regular and appropriate intensity exercise for the immune system in respiratory infections [87] [88] [89] like COVID-19. Other positive effects on host factors, such as reduction in oxidative stress, increased physical and cardiopulmonary conditioning, attenuation of systemic proinflammatory and pro-thrombotic states, the prevention or reduction of overweight, improvements in glycemic, insulinemic, and lipidic metabolisms, in addition to the enhancement of the vaccination response, show how well ph works [90].

It is rightly said by the Nobel Prize-winning biologist Joshua Lederberg, "The single biggest threat to man's continued dominance on the planet is the virus." The human body is an incredible piece of architecture with systems that have 
always perplexed researchers due to its unique capacity to adapt to changing circumstances. It has a defensive system to defend it from pathogens of all kinds, especially viruses. "The Immune System" is the name given to this system. The body must first detect the threat, whether it is a pathogenic agent or an immunization, as with any immune system challenge. The innate immune system is usually responsible for the initial detection, though B-cells may also be involved. When the immune system detects epitopes on antigens, the detection process begins. Epitopes on antigens are tiny sub-regions that simulate immune recognition. The innate immune system will then respond to the stimulus in a variety of ways. These innate immune components will opsonize or bind to the agent, assisting antigen-presenting cells like macrophages or monocytes engulfing it. These antigen-presenting cell(s) will next digest the pathogenic agent's antigens and insert them, together with the MHC protein, onto the antigen-presenting cell's surface [91]. If the antigen is a viral antigen, it will be linked to MHC I protein and presented to a CD8 cell by the antigen-presenting cell, triggering cell-mediated immunity. Suppose the antigen is a bacterial or parasite antigen. In that case, it will be linked to MHC II protein and given to a CD4 cell by the antigen-presenting cell, triggering an antibody-mediated response [92].

All cells, including those in the immune system, require adequate and proper nourishment to function optimally. During infection periods, an "activated" immune system boosts the need for energy even more, with higher basal energy expenditure during fever, for example. As a result, optimal nutrition for the best immunological outcomes would be nutrition that supports immune cell functions, allowing them to initiate effective responses against pathogens while also allowing them to resolve the response quickly when necessary and avoiding any underlying chronic inflammation. The immune system's energy and food requirements can be satisfied through exogenous sources, such as the diet, or endogenous ones, such as body storage if dietary sources are insufficient. Some micronutrients and dietary components have essential roles in developing and maintaining a healthy immune system throughout life and reducing chronic inflammation. The amino acid arginine, for example, is required for macrophages to produce nitric oxide. At the same time, the micronutrients vitamin A and zinc govern cell division and hence are required for an excellent immune system proliferative response. Undernutrition, whether due to food shortages or famines in developing nations, or malnutrition resulting from periods of hospitalization in rich countries, is widely known to decrease immune function. The degree of the deficit, if there are nutrient interactions to consider, the presence of illness, and the person's age will all influence the severity of the impairment [28]. A single nutrient, like vitamin E, can have several immunological effects, such as functioning as an antioxidant, inhibiting protein kinase C activity, and potentially interacting with enzymes and transport proteins [29]. Excessive intake of several micronutrients has also been linked to weakened immunological responses. In malaria-endemic areas, for example, iron supplementation can increase morbidity and mortality. In addition to the potential for nutrition to effectively treat 
immune deficiencies caused by inadequate intake, there is much research to see if specific nutritional interventions can improve immune function in sub-clinical situations and thus prevent the onset of infections or chronic inflammatory diseases [93] [94]. The following diagram (Figure 1) shows the flow of how can improve the immune system.

\section{Immune System}

A sophisticated and complex mechanism in the human body is alert and active throughout the day to ensure the body's safety against all sorts of diseases and pathogens in its surroundings, termed the "immune system" of the body. The human immune system can be roughly divided into three layers. The first layer consists of skin, cilia, and mucus in the respiratory tract; acid and enzymes in the stomach; lactic acid in the vagina; lysozyme enzyme in tears, saliva, urine, and sweats and blood clotting on skin being exposed to the outside due to laceration or pricking. The main task of this layer is to trap the invading dust particles, germs, and bacteria from entering the body at all and flushing them out in the instance they manage to get in through any opening. The second layer consists of lymphocytes and phagocytes; the complement system comprises 25 different defense proteins; interferon and histamine. Whose essential function is to kill any foreign particle on-site and alert the whole system to watch out for any such similar particle to do no further damage by similar such antigen. Anything that can trigger the immunity is termed an antigen.

The immune system is the body's innate defense system against attackers. White blood cells, which mainly consist of lymphocytes, make up the immune system's cells. T-cells and B-cells are the two main classifications of lymphocytes. $\mathrm{T}$-cells have receptors on their surfaces that communicate with molecules present in other body cells. $\mathrm{T}$-cells recognize the matter in the body as a foreign material, for example, virus or bacterium, by binding to the molecules. T-cells either kill the invader individually or collaborate with other immune cells to coordinate an attack after they have been identified. B cells, on the other hand, produce antibodies that are unique to a foreign substance. The attackers are then tracked down by the antibodies, which adhere to antigens on the alien substance's surface. An antibody may either neutralize the foreign agent or label it for destruction by other immune system members by binding to the antigen.

Furthermore, two forms of the immune system are observed within the body: the innate immune system and the adaptive immune system. The natural immune system is from birth and includes macrophages, dendritic cells, biological

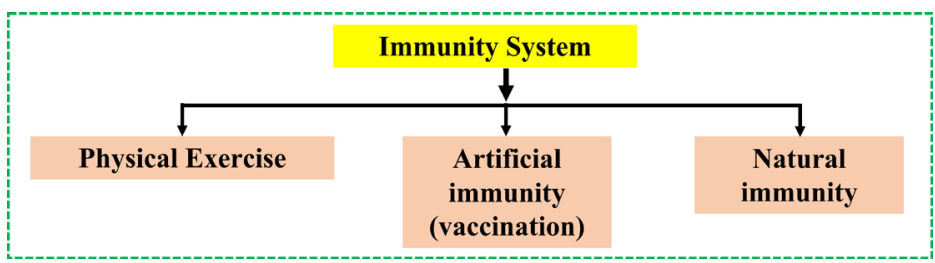

Figure 1. The flow diagram to improve the immune system. 
kill cells, neutrophils, and cytokines. At the same time, the adaptive immune system can be changed and increase and decrease in levels. The cells that are a part of the adaptive immune system include T \& B lymphocytes and their products (antibodies and cytokines).

In addition to B-lymphocytes and T-lymphocytes, another type of white blood cell helps fight infection called macrophages. Macrophages are white blood cells that destroy foreign cells such as germs, viruses, and dead or dying cells. Macrophages then leave behind parts of the invading cells called antigens. The body can make corresponding antibodies that recognize and foreign antigens and attack them, stimulating an immune response. Creating the corresponding antibody against the alien virus such as COVID-19 can take time and typically requires several days. It can take even longer for the body to fight off the foreign invader from creating the antibodies. After the body has fought off the foreign invader, a few T-lymphocytes, or memory cells, go into action rapidly if the body comes in contact with the same virus again. Thus, the body is quickly able to attack the foreign cells before they can accumulate. Thus, providing a form of immunity from the foreign pathogen [28].

\subsection{Impact of Hormones in the Human Immune System}

The presence of hormones influences the immune system's activity. Hormones secreted by almost all glands play a part in keeping us fit and sustaining stable and controlled internal physiological habits, both directly and indirectly. Researchers discovered many times that sex hormones from the reproductive system (Testes, Ovary, Uterus, Placenta) influence the immune system due to hormone receptors on immune cells [95]. As their experimental data suggests, when sex hormones (hormones released from Testes, Ovary, Uterus, Placenta as shown in Table 1) and immune cells make an interaction. These Cytokines' releases determine the number of physical factors called proliferation/apoptosis, differentiation, and maturation of different types of immunecytes resulting in inflammatory or autoimmune diseases. American Cancer Society reported in 2019 that these Cytokines help boost anti-cancer activity by sending signals that can help make abnormal cells die and normal cells live longer [96]. Therefore, sex hormones positively affect the immune system in various ways by increasing the number of circulating immune cells and triggering the hormones required to strengthen the immunity.

On the other hand, the endocrine system uses the hormones released to coordinate and monitor internal metabolism, energy levels, fertility, and the body's reaction to damage, stress, and diseases it is likely to avoid. A network of signal molecules (cytokines, hormones, and neurotransmitters) that function on a similar collection of receptors connects the immune, endocrine, and central nervous systems. The following figure (Figure 2) shows the influence of different techniques on the immune system. There is a bidirectional influence between the immune and CNS (central nervous system or brain) and the immune and endocrine system and CNS. Researchers found that sex hormones act directly on the 
Table 1. Source glands and organs of hormones.

\begin{tabular}{|c|c|c|}
\hline Gland and Organ & Released Hormones & $\begin{array}{l}\text { Role in } \\
\text { Immunity }\end{array}$ \\
\hline $\begin{array}{l}\text { Central Nervous System: } \\
\text { Pituitary gland (brain) }\end{array}$ & $\begin{array}{l}\text { Growth hormone (GH), Thyroid Stimulating } \\
\text { Hormone (TSH), Adrenocorticotropic hormone } \\
\text { (ACTH), Follicles-stimulating hormone (FSH), } \\
\text { MSH, Luteinizing hormone (LH), Prolactin, } \\
\text { Vasopressin, Serotonin, Endorphin }\end{array}$ & Yes \\
\hline $\begin{array}{l}\text { Central Nervous System: } \\
\text { Hypotha-lamus (brain) }\end{array}$ & $\begin{array}{l}\text { TRH, CRH, GHRN, Dopamine, } \\
\text { Somatostatin, Vaso-pressin, Oxytocin }\end{array}$ & \\
\hline CNS: Pineal gland (brain) & Melatonin & Yes \\
\hline Thyroid and Parathyroid & T3, T4, Calcitonin, Parathyroid hormone (PTH) & \\
\hline Stomach & $\begin{array}{l}\text { Gastrin, Ghrelin, Histamine, } \\
\text { Somatostatin, Neuropep-tide Y }\end{array}$ & \\
\hline Thymus & Thymopoietin & \\
\hline Pancreas & Insulin, Glucagon, Somatostatin & \\
\hline Kidney & Calcitriol. Renin, Erythropoietin & \\
\hline Testes & Androgens, Estradiol, Inhibin & \\
\hline Uterus & Prolactin, Relaxin & \\
\hline Ovaries, Placenta & Estrogens, Progesterone & \\
\hline Adrenal & $\begin{array}{l}\text { Androgens, Glucocorticoids, } \\
\text { Adrenaline, Noradrenaline }\end{array}$ & Yes \\
\hline Liver & IGF, THPO & Yes \\
\hline
\end{tabular}

CNS or brain or on the brain hormones that affect the immune response [97]. Therefore, the hormones and glands that have a direct impact on the immunity system are, Central Nervous System (Pituitary and Hypothalamus glands), Reproductive organs (Testes, Ovary, Uterus, Placenta glands), Adrenal gland, Pancreas glands, and Kidney released hormones (Table 1).

According to Dr. Ananya Mandal, published in the News Medical, hormones are chemical messengers secreted directly into the blood, which carries them to organs and tissues of the body to exert their functions. There are many types of hormones that act on different aspects of bodily functions and processes. Some of these include [98] [99]:

- Development and growth: Pituitary gland hormones.

- Metabolism of food items: Insulin, the hormone released from the pancreas.

- Sexual function and reproductive growth and health: testosterone, estrogen.

- Cognitive function and mood: Dopamine, Serotonin, Oxytocin, etc.

- Maintenance of body temperature and thirst: Hypothalamus hormones.

- Maintaining salt and water balance of the body: Adrenal gland hormones.

- Reduce feeling with pain and help to deal with stress: Endorphins.

- Affects immunity: Hormones released from Uterus, Ovary or Placenta and CentralNervous Systems or brain (Pituitary, Hypothalamus, Pineal). 


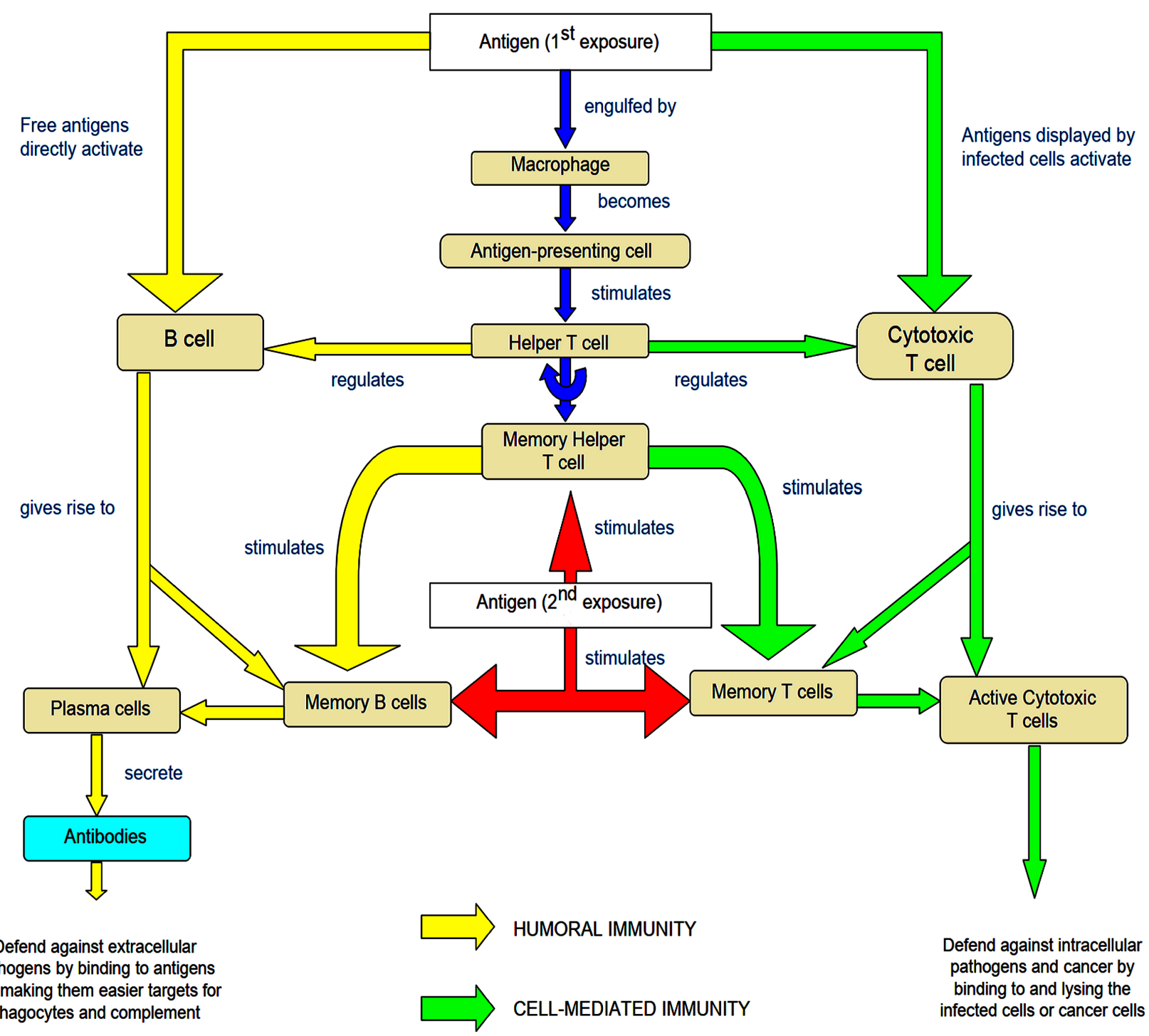

Figure 2. Immune System from first antigen exposure to the formation of anti-bodies [103].

\subsection{Hormones for a Better Mood}

Physical exercise improves many health effects, including mental health and a positive impact on serotonin levels in the brain, improves mood to enhance appetite and sleep patterns better, and increases dopamine levels [100]. Aerobic exercises, such as walking, running, swimming, bicycling, fast walking, jogging, and light hiking, seem to be the most important. Meditation is well-known for its many health effects, including improved sleep and stress reduction (Figure 3). Meditation has the effect of helping to balance hormone output, especially dopamine, which negatively influences mood and physical health. Dopamine and serotonin synthesis may be affected by daily stress (Figure 4, Figure 5). It is rightly said that "Laugh is the best medicine." It can benefit by reducing anxiety and stress and improving low mood by increasing dopamine and endorphin levels [101] [102] [103]. 


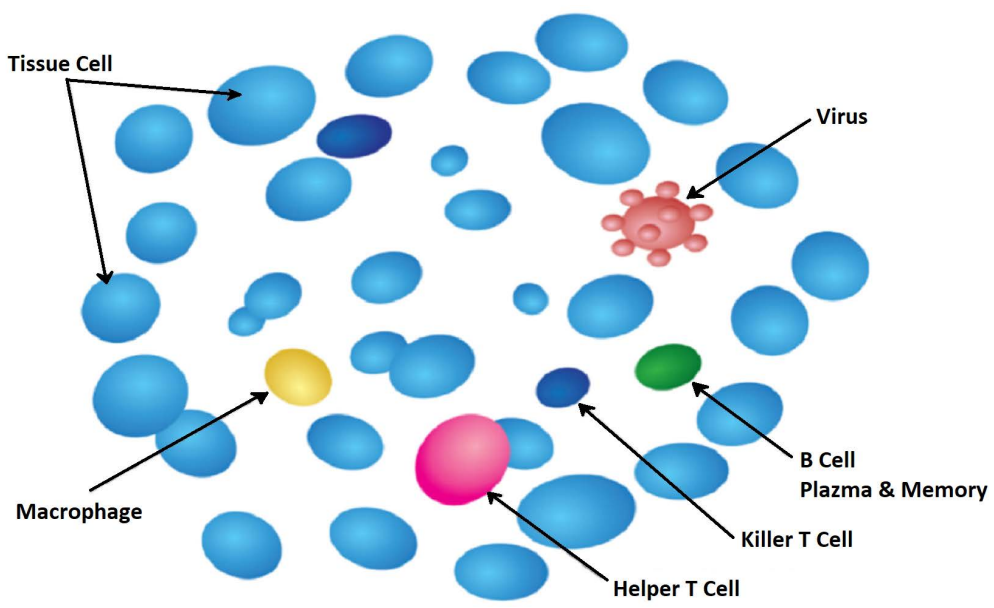

Figure 3. Immune system has different ways of fighting infection [103].

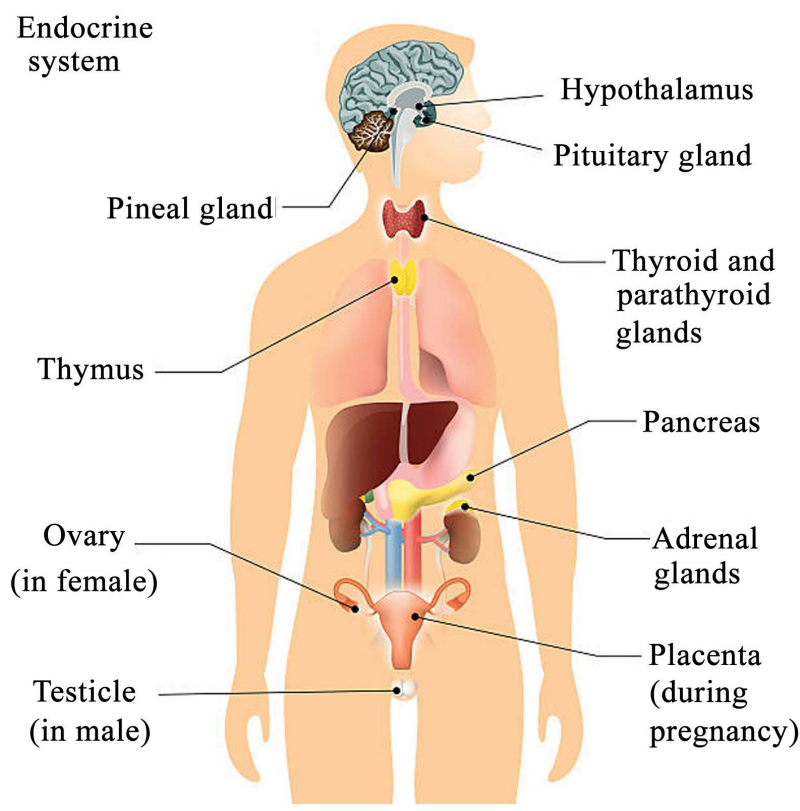

Figure 4. Human body hormones [99] [104].

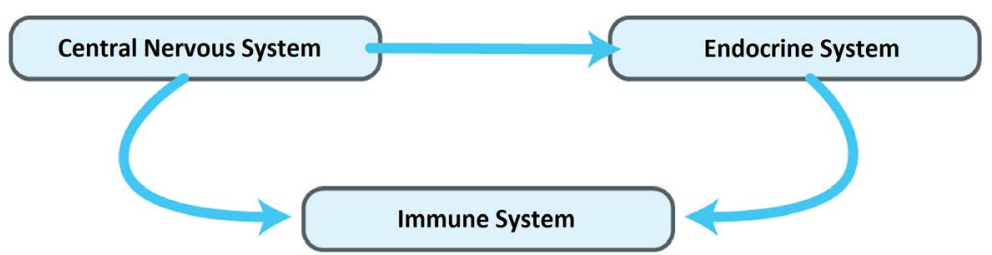

Figure 5. Hormones from endocrine and CNS (brain) with significant effect in immune system.

- Dopamine: Dopamine is a chemical that carries impulses from the body to the brain and is known as the "feel-good" hormone. It is an integral component of the brain's reward system. Dopamine is responsible for influencing a person's actions and emotional reactions and is linked to pleasurable sensations such as finishing a task, celebrating, and consuming food. Dopamine 
balance is essential for physical and mental health, and a lack of it can substantially affect a person's quality of life, physically and mentally. If they are worried about their dopamine levels, some drugs and therapies can help alleviate symptoms.

- Serotonin: Serotonin is a neurotransmitter that regulates mood, thoughts, sleep, appetite, metabolism, learning capacity, memory, and hormonal function. It may be increased by meditation, exercise, and sun exposure, among other things. Researchers conclude that low serotonin levels play a role in depression.

- Oxytocin: Oxytocin, also known as the "love hormone" is a hormone produced in response to sexual attraction and is essential for reproduction, breastfeeding, and close parent-child bonding. In relationships, this hormone can aid loyalty, empathy, and bonding.

- Endorphins: Endorphins, the body's natural pain reliever, increase rewardproducing behaviors and are produced in response to stress or discomfort.

- Cortisol: Cortisol is the body's primary stress hormone, a naturally occurring steroid hormone that regulates anxiety, motivation, and anxiety by interacting with various brain areas. It helps the body manage carbs, fats, and proteins, reduces inflammation, lowers blood pressure, raises blood sugar, regulates the sleep/wake cycle, improves stamina so we can withstand stress, and restores equilibrium. Cortisol receptors absorb and use the hormone in a variety of ways. For example, cortisol can change or shut down functions while the body is on high alert. The digestive and reproductive systems, the immune system, and also development cycles are examples of these. The amount of cortisol should decrease, and the pulse, blood pressure, and other body systems should return to normal. It may also cause a variety of health issues, such as anxiety and depression, headaches, heart failure, memory and attention problems, digestive issues, difficulty sleeping, weight gain, and so on. Cortisol levels fluctuate during the day. Cortisol levels in the body usually are highest in the morning and lowest at night. Cortisol levels can also fluctuate; they are secreted in higher amounts during the body's stress response and are responsible for various stress-related changes. Stress management can help to lower cortisol levels in the body. To maintain cortisol levels stable and under control, stimulate the body's calming response once the fight or flight response has occurred, calm the body with various stress relief strategies, and make behavioral adjustments to prevent the body from responding to stress in the first place. Breathing exercises, exercise, listening to music, meditation, yoga, and other relaxation techniques may help the body retain stable cortisol levels. Learning stress control strategies and maintaining a low-stress lifestyle is particularly critical. While cortisol is an essential and beneficial part of the body's stress response, it is also essential for trigger the calming response so that the body's functions can return to normal after a traumatic incident. 


\section{Improving Immune System by Physical Activities}

The practice of physical exercises acts as a modulator of the immune system in the body. During and after physical activity, pro and anti-inflammatory cytokines are released, lymphocyte circulation increases, as well as cell recruitment [104] and thus, improves sensitivity to Leptin and Insulin, which strengthens the immune system of the body [77] [78]. Research [105] found that the impact of exercise on innate and acquired immune parameters consisting of magnitude, the direction of changes, and recovery time is dependent on the intensity of exercise that a person consumes or undergoes [106]. For example, when an athlete participates in high-performance sports, the duration and load of training are much intense.

Immune function can be compromised at the high-performance end of the physical activity spectrum and place an individual at increased risk of infection, as demonstrated in Figure 3. However, there is a general concept that regular bouts of up to 45 minutes of moderate exercise benefit the host immune defense (Figure 6). The study was carried out on animals and human beings, particularly in older adults and people with chronic diseases. Consequently, several clinical and epidemiologic data based on scientific research supports the impacts of exercise on the immune system, including the American College of Sports Medicine position papers and the Surgeon General's report on physical activity and health [107]. However, these effects are highly variable, depending on the nature and intensity of exercise. The authors currently define vigorous exercise as 5 to 60 minutes at $70 \%$ to $80 \%$ aerobic capacity and moderate exercise as 5 to $60 \mathrm{mi}$ nutes at $40 \%$ to $60 \%$ aerobic capacity, which plays a positive role in building the body's immune systems [28].

The benefits of moderate exercise (20 to 30 minutes), 55\% - 70\% of max pulse rate-have improved the adaptive immune system. Moderate exercise promotes the flow of lymph and the immune cells and antibodies. Lymph vessels depend on body motion to move the lymph along. It improves the blood flow of the cardiovascular system, helping to flush toxins and germs from the body through the excretory system via urine and sweat. It increases the delivery of oxygen through the bloodstream, improving the body's resistance. Exercise also decreases the inflammation in the body, which in turn improves immunity. Studies done on

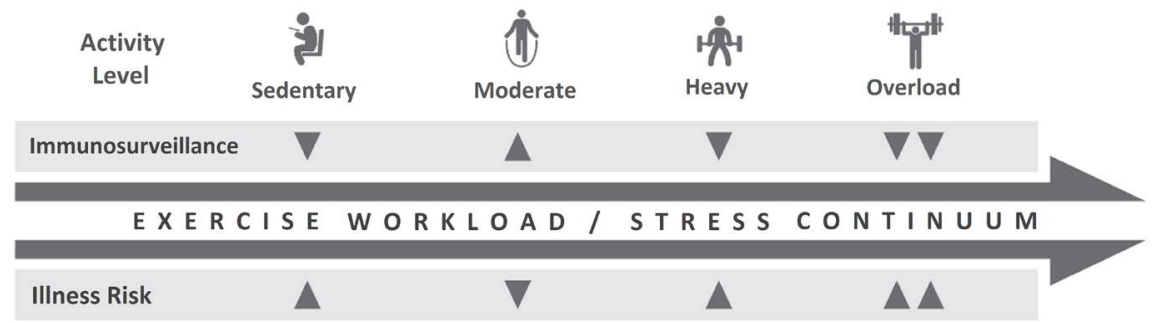

Figure 6. Model of exercise workload/stress continuum, showing the relation between immune surveillance measures and risk of illness as the exercise workload is increased from moderate to heavy and overload. 
mice have shown that mice who exercised regularly had less severe symptoms than those who did not regularly exercise [108]. Lastly, exercising can relieve mental and emotional stress linked to suppressed immunity and increased illness.

Yoga is a mind-body tradition that originated in ancient India about 500 BC to form effective relaxation and spiritual activities. Yoga is a Sanskrit term that means "unity" or "conjunction" and refers to the concept of uniting the body, mind, and spirit. It is gaining popularity as a therapeutic intervention, and it evolved not only as a method of physical exercise but also as a system of healing [39]. Yoga practice can be beneficial because it blends the benefits of physical exercise with the help of mindfulness. Studies show that Yoga can improve cell-mediated immunity. As a result, it may potentially treat diseases like AIDS or improve immune function in general, such as counteracting immune function suppression in challenging conditions [36].

About three decades of research has shown the effectiveness of yoga activities, including mediation, in restoring homeostasis in non-communicable diseases by reducing stress and encouraging a safe lifestyle. The interconnectedness of the mind and body and the correction of imbalances have been extensively researched to establish a systemic basis for human well-being. Asana, pranayama, and meditation are yoga exercises that can help cultivate the mind by strengthening the willpower that makes the immune system healthy. Both yoga activities include intense relaxation, which can help relieve pressures and strains, which can help avoid immune suppression, impairing the body's resistance to infectious bacteria and viruses [109].

A new study looks at the connection between exercise and mental health [41] [110]. According to research, physical activity can help improve mental health, and those with serious mental illnesses are less physically active than those in good mental health. The study discovered that the fear and tension associated with the COVID-19 pandemic has made people less likely to partake in physical exercise that may help them improve their emotional health and manage stress, anxiety, and depression [111]. Stress relief, pain relief, and better sleep have all become more critical motivators for exercisers. People who had cut their physical exercise the most after the pandemic had the most mental health problems. Additionally, more support is needed for those trying to preserve their mental and physical well-being during difficult periods, such as the COVID-19 pandemic, therapeutic support to their physical exercise during hard times to reduce the pandemic's pressure avert the mental health crisis [76].

Physical activity and exercise are almost as successful as pharmacological treatments in combating cardiovascular disease and lowering mortality. People with a severe mental disorder, on the other hand, face a variety of obstacles to physical activity and fitness, including elevated levels of perceived discomfort, somatic comorbidities, depressed mood, and a loss of self-confidence and social support, to name a few [79].

Thus, meditation, exercise, journaling, yoga, adequate sleep, and other mind- 
fulness techniques are some of the activities that can help us control stress [65] [70] [112]. Whether virtually or in person, seeing a certified psychiatrist or therapist can also be beneficial [80]. Some studies indicate the following supplements may strengthen the body's immune response [113] [114]:

- Vitamin C: According to a review in over 11,000 people, taking $1000-2000$ $\mathrm{mg}$ of vitamin $\mathrm{C}$ per day reduced the duration of colds by $8 \%$ in adults and $14 \%$ in children.

- Vitamin D: Vitamin D deficiency may increase the chances of getting sick, so supplementing may counteract this effect. Adequate levels of vitamin D do not seem to provide extra benefits.

- Zinc: In a review of 575 people with the common cold, supplementing with more than $75 \mathrm{mg}$ of zinc per day reduced the duration of the cold by $33 \%$.

\section{Artificial Immunity (Vaccination)}

Patients who have been physically inactive for at least two years have a higher risk of death from covid. A study said covid patients who were physically inactive or did not exercise were more likely to be taken to hospital, intensive care unit or die. The study was published in the British Journal of Sports Medicine. The study was conducted on about 50,000 people. It has been said that physical inactivity is one of the health risks of patients with Covid. The average age of the patients in the study was 48 years. Three out of every five were women. Concerned researchers say that smoking, obesity, and anxiety are also among the health risks of Covid. "Physical inactivity is a severe health risk," the study said [87].

For example, COVID-19 vaccines allow us to develop immunity to the COVID19 virus without contracting the disease [115] [116]. As previously said, various types of vaccines provide defense in different ways. However, almost all vaccines cause the body's T-lymphocytes and B-lymphocytes to build a "memory" of how to combat the same virus if it ever contaminates the body again (Figure 7, Figure 8).

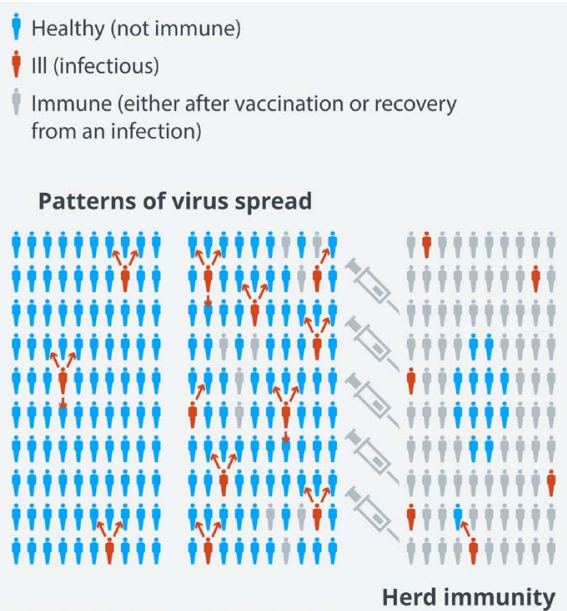

Figure 7. Diagram of process to achieve herd immunity [47] [104]. 


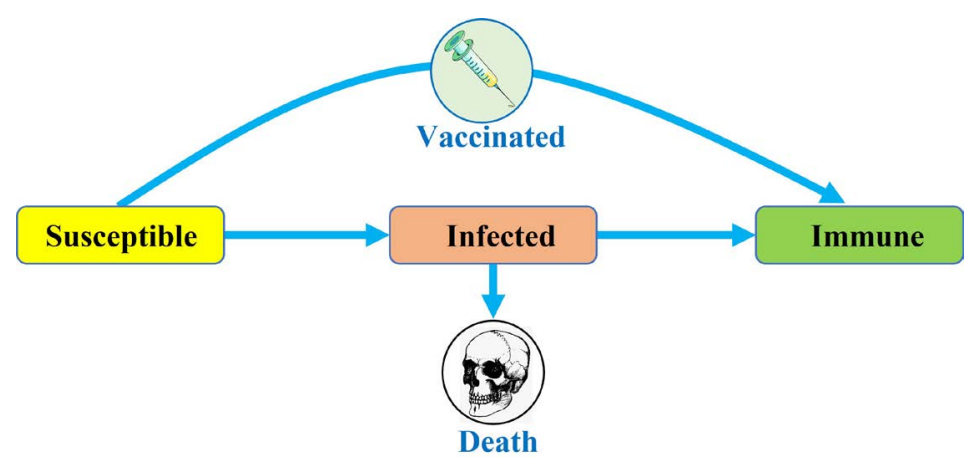

Figure 8. Diagram of process to achieve herd immunity.

After initial injection, the body usually needs a few weeks to develop and produce T-lymphocytes and B-lymphocytes. Since the vaccine takes some time to take its full effect, a person can become infected with the COVID-19 virus shortly after vaccination. Other symptoms, such as fever, muscle aches, etc., may appear after immunization, but this is just a common indication that the body is developing immunity to the virus.

The vaccines operate in various ways to get our bodies to know and defend us from the COVID-19 virus. No COVID-19 vaccines can give us COVID-19. There are three main types of COVID-19 vaccines that are existent which are as follows:

- mRNA vaccines: Genetic materials of the COVID-19 virus are put into the body that gives our cells the tools necessary to make proteins unique to the virus. Upon completing the instructions to synthesize the proteins that are unique to the virus, our body then destroys the genetic material from the vaccine. Our body can recognize the foreign protein and build up the corresponding T-lymphocytes and B-lymphocytes to fight the virus if ever found in the body.

- Protein sub-unit vaccines: A sub-unit vaccine introduces one or more antigens to the immune system without adding entire or fragmented pathogen particles. Antigens may be any compound, such as proteins, peptides, or polysaccharides, and the term "sub-unit" merely means that the antigen is a fragment of the pathogen. The vaccine is absolutely "dead" much as inactivated vaccines and therefore poses a lower risk. Instead of injecting the whole germ, a sterile spike protein present in the virus's wall is used as a protein subunit vaccine. Our immune system acknowledges that the proteins are foreign to the body and begin to produce T-lymphocytes and antibodies in response to vaccination. Even if we are contaminated in the future, our memory cells will recognize the infection and will be able to fend it off quickly.

- Vector vaccines: The vaccine is a weakened variant of a live virus that is not the COVID-19 virus but contains genetic material from the COVID-19 virus. If the viral vector has entered the body, the genetic material instructs cells to produce COVID-19-specific proteins. Our body's cells can create copies of the 
protein using these instructions enables our T-lymphocytes and B-lymphocytes to know how to battle the virus in the future if they become infected [117].

\section{Natural Immunity and Hard Immunity}

Herd immunity is described as when a large percentage of a population becomes resistant to an infectious disease, decreasing the disease's ability to spread. It is a resilience made up of blood proteins that our bodies resist foreign invaders, including bacteria and viruses. Antibodies combat these invaders by increasing body temperature, killing bacteria or viruses, and protecting us from illness. To gain herd immunity, $70 \%-90 \%$ of a population must have immunity, depending on how infectious the virus is. Suppose we assume that $80 \%$ of a population is immune to infection. In that case, this implies that 4 out of every five individuals who come into contact with an infected individual will not become infected (and therefore will not transmit the disease). In this way, infectious disease transmission is slowed or eradicated in some particular cases.

Herd immunity (naturally or artificially) is achieved chemically, while the human immune system is the body's protective system against foreign pathogens, which is a standard and by-born phenomenon (Figure 3). However, several evidence-based preventive strategies to strengthen the immune system include eating healthy, exercise and physical activities, and managing stress. Recently, J. J. Rucklidge, a professor at the University of Canterbury, and G. Schofield, professor at the Auckland University of Technology, identified three modifiable risk factors [71] as shown in Table 2.

Table 2. Ways to get a stronger immune system before we perceive a herd immunity.

\begin{tabular}{|c|c|c|}
\hline Diet & Exercise & Relieve from Stress \\
\hline $\begin{array}{l}\text { Vitamins C and D, as well as } \\
\text { zinc, have been described as } \\
\text { important for improving } \\
\text { immunity during one's life. }\end{array}$ & $\begin{array}{l}\text { High cardio-respiratory } \\
\text { (lung and heart) health is } \\
\text { linked to less respiratory } \\
\text { ailments and longer survival. }\end{array}$ & $\begin{array}{l}\text { Meditation, mindfulness, } \\
\text { cognitive-behavioral therapy, } \\
\text { getting enough sleep, and eating } \\
\text { a healthy diet will all help us cope } \\
\text { with the negative effects of stress. }\end{array}$ \\
\hline $\begin{array}{l}\text { Consuming real entire foods } \\
\text { such as fruits and vegetables, } \\
\text { almonds, legumes, fish, and } \\
\text { healthier fats while avoiding } \\
\text { ultra-processed foods. }\end{array}$ & $\begin{array}{l}\text { Budget time and priorities } \\
\text { walking at a } \\
\text { Minimum. }\end{array}$ & $\begin{array}{l}\text { Receiving adequate nutrients like } B \\
\text { vitamins and a broad spectrum of } \\
\text { minerals like magnesium, copper, } \\
\text { and zinc at periods of stress has a } \\
\text { beneficial effect onphysical health. }\end{array}$ \\
\hline $\begin{array}{l}\text { In both children and adults, } \\
\text { a nutritious and } \\
\text { nutrient-dense diet is linked } \\
\text { to a reduced risk of mental } \\
\text { health conditions. }\end{array}$ & $\begin{array}{l}\text { Engage in and perform a } \\
\text { more vigorous activity } \\
\text { regularly, in optimum } \\
\text { amount. May go outside and } \\
\text { be with important others. }\end{array}$ & $\begin{array}{l}\text { Immunity is negatively affected } \\
\text { by stress. It causes the cortisol } \\
\text { response to be disrupted, which } \\
\text { may suppress immune function. }\end{array}$ \\
\hline $\begin{array}{l}\text { Low levels of specific } \\
\text { nutrients, such as vitamin D, } \\
\text { have been identified as } \\
\text { COVID-19 risk factors. }\end{array}$ & $\begin{array}{l}\text { The more the better, as long } \\
\text { as it is not achieved to the } \\
\text { point of exhaustion for the } \\
\text { individual's fitness level. }\end{array}$ & $\begin{array}{l}\text { Chronic stress may reduce the } \\
\text { number of lymphocytes in the } \\
\text { body. An individual is more } \\
\text { likely to catch a virus owing to } \\
\text { poor lymphocyte count. }\end{array}$ \\
\hline
\end{tabular}


The natural yet risky way to attain immunity is by being infected by the disease. Resilience against infectious viruses is developed generally due to surviving viral infections; this provides the requisite antibodies to fend off potential infections. A vaccination will give a person artificial immunity to a disease, preventing the virus from spreading to those that cannot be vaccinated, such as newborns, pregnant mothers, and people with pre-existing medical conditions. On the other hand, herd immunity can be obtained when a sufficient number of individuals catch the illness and survive. Natural immunity may contribute to building herd immunity, but it may not be as effective as vaccines, given the health hazards it can pose to many people [118]. When more people in a community are immune, a disease cannot move as quickly and is less likely to find people who lack immunity. Regarding COVID-19, 50\% - 80\% of people are expected to remain protected against the virus achieving herd immunity if they consume the vaccines, a recent article reported [119]. Most people infected with COVID-19 produce an immune response within a few weeks, but we do not know how robust or extensive the immune response is, how long it lasts, or how it varies between people. There have also been cases of individuals infected with COVID-19 a second, third, or fourth time.

Herd immunity is obtained in two ways: spontaneously or chemically. It occurs when a herd has gained immunity either by vaccination or prior infection. Recently, the World health organization (WHO) advocates that herd immunity is achieved by vaccination rather than encouraging an epidemic to spread to any part of the population. Vaccines work by simulating pathogens in our bodies and training our immune systems to produce disease-fighting proteins known as antibodies. Herd protection to COVID-19 is designed to keep nearly $10 \%$ of susceptible populations (pregnant mothers, the very ill, and the elderly) healthy and shielded from the disease. If we vaccinate $100 \%$ of the "target" population, we will only achieve $50 \%$ protection for the whole community; we will not earn more than $50 \%-60 \%$ vaccination. If $50 \%$ herd immunity is needed, it is clear that vaccination alone would not be enough to meet the target.

The percentage of the population who must be vaccinated against COVID-19 to achieve herd immunity is unknown. However, it varies depending on the community, the vaccine, the communities targeted for vaccination, and other variables. WHO is also factoring in the intensity and duration of a person's reaction, which varies depending on whether the infection is asymptomatic, moderate, or extreme. In this field, further research is needed. Immune responses can occur in even asymptotic individuals. Herd immunity is not ensured, even though $70 \%$ of the population is contaminated for herd immunity, which is considerable. To put it another way, more than 120 million individuals would have to be infected with COVID-19 before herd immunity is achieved. If a $1 \%$ death rate is used, the number of individuals who die will be enormous.

CDC found that the mRNA vaccines developed by Pfizer-BioNTech and Moderna are highly effective against COVID-19 because, after the first dose, those vaccines prevented 80 percent cases and 90 percent after the second dose. 
Those researchers found that the mRNA vaccine provides immunity for at least six months, but they cannot be sure if immunity will wane after that or any booster dose will be needed to take regularly [120].

Vaccines are very effective at preventing severe COVID-19, including asymptotic ones. President of American Medical Association Dr. Susan Bailey said, "There is more evidence showing that transmission of the virus from a vaccination is likely deficient". The good news is that studies showed that vaccines reduce transmission to some extent, but they do not know how much the vaccines will reduce transmission [121]. Pfizer has recently released their data showing that the vaccine was highly influential in South Africa, where the B.1.351 variant is common. The New England Journal of Medicine on March 16, 2021, shows that the Oxford-AstraZeneca vaccine is only 10 percent effective against the South African variant [122] [123] [124].

Once the people are vaccinated, transmission becomes less and protects people by reducing disease spread. In Bangladesh till April 8, 2021, 5,498,172 first shot has received, which is about 1.7 percent of the country's population of 170 million, and we need to give $125,000,000$ of $80 \%$ of the population. We need reliable data to understand trends and patterns of death, and the vaccine alone will not be enough to control the pandemic. The vaccine does not offer immediate protection against disease. The accurate and sufficient data is more important in fighting and prevent the pandemic. AstraZeneca said that the second shot of the vaccine could ensure that more consistent protection reaches 82 percent efficiency from 76 percent after the first shot. For now, washing hands, wearing masks, social distancing, physical activities, and other interventions that can reduce the rate of the infectious disease remain the best ways to lessen the destruction of Covid-19 to develop treatments and vaccines, also reduce deaths.

\section{Concluding Remarks}

We have discussed the physical activity is one of the only effective ways to stop chronic diseases. The evidence shows that regular physical activity strengthens the human system, reduces the danger of falling ill and dying from communicable diseases, and significantly increases the effectiveness of vaccination campaigns. Regular physical activity increases the amount of CD4+ T cells, which are liable for alerting the system of an attack and regulate its response. Physically active people are less likely to develop obesity, diabetes, respiratory and cardiovascular diseases also reduce stress and chronic inflammation, successively reducing the likelihood of adverse and fatal infections. An ideal diet is also a must to lead a healthy life. Proper diet boosts immune system, reduces the risk of mental health condition, gives energy to do physical exercise, and many more. We also discussed, yoga can play an essential role within the prevention and management of coronavirus.

\section{Acknowledgements}

The authors acknowledged to the anonymous reviewers for their constructive 
suggestions to improve the quality of the manuscript significantly. The authors M. Kamrujjaman and M. Shahidul Islam research were partially supported by Centennial Research Grant, University of Dhaka.

\section{Author Contributions}

Conceptualization, M. S. I, M. K. and K. M. A. K.; methodology, I. C., M. A. M., and M. I.; investigation, M. S. I; resources, M. S. M, M. K. U; original draft preparation, I. C., M. A. M., and M. I.; review and editing, M. S. I, M. K. and K. M. A. K. and M. S. M., supervision, M. K. All authors have read and agreed to the published version of the manuscript.

\section{Conflicts of Interest}

The authors declare that they have no conflict of interest.

\section{References}

[1] DeRoo, S.S., et al. (2020) Planning for a COVID-19 Vaccination Program. JAMA, 323, 2458-2459. https://doi.org/10.1001/jama.2020.8711

[2] WHO (2020) Coronavirus (COVID-19) Dashboard. https://covid19.who.int

[3] (2021) Global COVID-19 Death Toll More than Double the Estimates: Study. https://www.aljazeera.com/news/2021/5/7/global-covid-19-death-toll-more-than-do uble-the-estimates-study

[4] How COVID Vaccines Work against the Delta Variant, 16 June 2021. https://www.aljazeera.com/news/2021/6/16/how-covid-vaccines-work-against-delta -variant

[5] Chowdhury, M.A., et al. (2020) Immune Response in COVID-19: A Review. Journal of Infection and Public Health, 13, 1619-1629. https://doi.org/10.1016/j.jiph.2020.07.001

[6] Makhlouf, A.M., El-Shennawy, L. and Elkaranshawy, H.A. (2020) Mathematical Modelling for the Role of CD4+ T Cells in Tumor-Immune Interactions. Computational and Mathematical Methods in Medicine, 2020, Article ID: 7187602. https://doi.org/10.1155/2020/7187602

[7] Sitlinger, A., Brander, D.M. and Bartlett, D.B. (2020) Impact of Exercise on the Immune System and Outcomes in Hematologic Malignancies. Blood Advances, 4, 1801-1811. https://doi.org/10.1182/bloodadvances.2019001317

[8] Chowdhury, M. (2021, April 11) Recommendation for the Gap between Two Doses of COVID-19 Vaccine. The Daily Star.

[9] Ellis, R. (2021) Pfizer, Moderna Say Booster Shots Probably Needed. https://www.webmd.com

[10] McCallum, K. (2020) What Happens If You Miss Your 2nd COVID-19 Shot? https://www.health.com/condition/infectious-diseases/coronavirus

[11] Druss, B.G. (2020) Addressing the COVID-19 Pandemic in Populations with Serious Mental Illness. JAMA Psychiatry, 77, 891-892. https://doi.org/10.1001/jamapsychiatry.2020.0894

[12] (2020) Focusing on Vulnerable Populations during COVID-19. https://www.ncbi.nlm.nih.gov/pmc/articles/PMC7363379/pdf/acm-publish-ahead-o f-print-10.1097.acm.0000000000003571.pdf 
[13] (2020) India under COVID-19 Lockdown. The Lancet, 395, 1315.

https://www.thelancet.com https://doi.org/10.1016/S0140-6736(20)30938-7

[14] Kamrujjaman, M., et al. (2021) SARS-CoV-2 and Rohingya Refugee Camp, Bangladesh: Uncertainty and How the Government Took over the Situation. Biology (Basel), 10, 124. https://doi.org/10.3390/biology10020124

[15] Hassan, M., Mahmud, M., Nipa, K. and Kamrujjaman, M. (2021) Mathematical Modeling and COVID-19 Forecast in Texas, USA: A Prediction Model Analysis and the Probability of Disease Outbreak. Disaster Medicine and Public Health Preparedness, 1-12. https://doi.org/10.1017/dmp.2021.151

[16] Mahmud, M.S., Kamrujjaman, M., Jubyrea, J., Islam, M.S. and Islam, M.S. (2020) Quarantine vs. Social Consciousness: A Prediction to Control COVID-19 Infection. Journal of Applied Life Sciences International, 23, 20-27. https://doi.org/10.9734/jalsi/2020/v23i330150

[17] Kamrujjaman, M., Mahmud, M.S. and Islam, M.S. (2020) Coronavirus Outbreak and the Mathematical Growth Map of COVID-19. Annual Research \& Review in Biology, 35, 72-78. https://doi.org/10.9734/arrb/2020/v35i130182

[18] Islam, M.S., et al. (2020) Effect of Lockdown and Isolation to Suppress the COVID-19 in Bangladesh: An Epidemic Compartments Model. Journal of Applied Mathematics and Computation, 4, 83-93. https://doi.org/10.20944/preprints202004.0193.v2

[19] Sallis, R., et al. (2021) Physical Inactivity Is Associated with a Higher Risk for Severe COVID-19 Outcomes: A Study in 48440 Adult Patients. British Journal of Sports Medicine, 1-8. https://doi.org/10.1136/bjsports-2021-104080

[20] Antunes, R. (2021) Physical Activity and Mental Health in Covid-19 Times: An Editorial. Sleep Medicine, 77, 295-296. https://doi.org/10.1016/j.sleep.2020.10.007

[21] Azar, A.M. (2018) Physical Activity Guidelines for Americans. U.S. Department of Health and Human Services, Washington DC.

[22] Booth, F.W., Roberts, C.K. and Laye, M.J. (2012) Lack of Exercise Is a Major Cause of Chronic Diseases. Comprehensive Physiology, 2, 1143-1211. https://doi.org/10.1002/cphy.c110025

[23] Shahidi, S.H., Williams, J.S. and Hassani, F. (2020) Physical Activity during COVID-19 Quarantine. Acta Paediatrica, 109, 2147-2148. https://doi.org/10.1111/apa.15420

[24] Kaur, H., et al. (2020) Physical Fitness and Exercise during the COVID-19 Pandemic: A Qualitative Enquiry. Frontiers in Psychology, 11, Article ID: 590172. https://doi.org/10.3389/fpsyg.2020.590172

[25] WHO (2020, November 26) Physical Activity. https://www.who.int/news-room/fact-sheets/detail/physical-activity

[26] GOV.UK (2019) Physical Activity: Applying All Our Health.

[27] Sutherland, A. (2020) The One Organ Responsible for All Cases of High Blood Pressure and the Simple Exercises That Lower It.

https://avasuther.quora.com/The-one-organ-responsible-for-ALL-cases-of-high-blo od-pressure-and-the-simple-exercises-that-lower-it-1

[28] Brolinson, G.P. and Elliott, D. (2007) Exercise and the Immune System. Clinics in Sports Medicine, 26, 311-319. https://doi.org/10.1016/j.csm.2007.04.011

[29] Simpson, R.J., Campbell, J.P., Gleeson, M., Krüger, K., Nieman, D.C., Pyne, D.B., Turner, J.E. and Walsh, N.P. (2020) Can Exercise Affect Immune Function to In- 
crease Susceptibility to Infection? Exercise Immunology Review, 26, 8-22.

[30] Ahmed, K.R., Uddin, R., Kolbe-Alexander, T.L. and Khan, A. (2021) The Effectiveness of Physical Activity Interventions in Asian Children and Adolescents: A Systematic Review. Public Health, 194, 48-59. https://doi.org/10.1016/j.puhe.2021.02.011

[31] Nilsson, M., Kelly, P., Smith, J., Raine, L. and Biddle, S. (2020) Physical Activity for Cognitive and Mental Health in Youth: A Systematic Review of Mechanisms. Pediatrics, 138, e20161642.

[32] Li, A.W. and Goldsmith, C.-A.W. (2012) The Effects of Yoga on Anxiety and Stress. Alternative Medicine Review, 17, 21-35.

[33] Lubans, D., Richards, J., Hillman, C., et al. (2016) Physical Activity for Cognitive and Mental Health in Youth: A Systematic Review of Mechanisms. Pediatrics, 138, e20161642. https://doi.org/10.1542/peds.2016-1642

[34] Pascoe, M., et al. (2020) Physical Activity and Exercise in Youth Mental Health Promotion: A Scoping Review. BMJ Open Sport \& Exercise Medicine, 6, e000677. https://doi.org/10.1136/bmjsem-2019-000677

[35] Deslandes, A., et al. (2009) Exercise and Mental Health: Many Reasons to Move. Neuropsychobiology, 59, 191-198. https://doi.org/10.1159/000223730

[36] Falkenberg, R.I., Eising, C. and Peters, M.L. (2018) Yoga and Immune System Functioning: A Systematic Review of Randomized Controlled Trials. Journal of Behavioral Medicine, 41, 467-482. https://doi.org/10.1007/s10865-018-9914-y

[37] Pruett, S.B. (2003) Stress and the Immune System. Pathophysiology, 9, 133-153. https://doi.org/10.1016/S0928-4680(03)00003-8

[38] Sutherland, A. (2020) Reducing Blood Pressure Naturally Book-The Most Complete Guide to Cure High Blood Pressure without Medications.

[39] Swanson, A. (2019) Science of Yoga: Understand the Anatomy and Physiology to Perfect Your Practice.

https://www.yogajournal.com/meditation/science-of-meditation/science-behind-bei $\underline{\text { ng-present }}$

[40] Stewart, G. (2004) The Immune System. Chelsea House Publishers, New York.

[41] Sompayrac, L. (2019) How the Immune System Works. Sixth Edition, John Wiley \& Sons, Ltd., Hoboken.

[42] Clemente-Suárez, V.J., et al. (2020) Dynamics of Population Immunity Due to the Herd Effect in the COVID-19 Pandemic. Vaccines, 8, 236.

https://doi.org/10.3390/vaccines8020236

[43] Hossain, M.J. (2020) Is Bangladesh Moving toward Herd Immunity? Current COVID-19 Perspective. Bangladesh Journal of Infectious Diseases, 7, S63-S66. https://doi.org/10.3329/bjid.v7i00.50166

[44] Fine, P., Eames, K. and Heymann, D.L. (2011) Herd Immunity: A Rough Guide. Clinical Infectious Diseases, 52, 911-916. https://doi.org/10.1093/cid/cir007

[45] Desai, A.N. and Majumder, M.S. (2020) What Is Herd Immunity? JAMA, 324, 2113. https://jamanetwork.com https://doi.org/10.1001/jama.2020.20895

[46] Omer, S.B., Yildirim, I. and Forman, H.P. (2020) Herd Immunity and Implications for SARS-CoV-2 Control. JAMA, 324, 2095-2096.

https://doi.org/10.1001/jama.2020.20892

[47] Randolph, H.E. and Barreiro, L.B. (2020) Herd Immunity: Understanding COVID-19. Immunity, 52, 1-5. https://doi.org/10.1016/j.immuni.2020.04.012 
[48] Metcalf, C.J.E., Ferrari, M., Graham, A.L. and Grenfell, B.T. (2015) Understanding Herd Immunity. Trends in Immunology, 36, 753-755. https://www.thelancet.com https://doi.org/10.1016/j.it.2015.10.004

[49] Edenfield, T.M. and Saeed, S. (2012) An Update on Mindfulness Meditation as a Self-Help Treatment for Anxiety and Depression. Psychology Research and Behavior Management, 5, 131-141. https://doi.org/10.2147/PRBM.S34937

[50] Anderson, R.M., Vegvari, C., Truscott, J. and Collyer, B.S. (2020) Challenges in Creating Herd Immunity to SARS-CoV-2 Infection by Mass Vaccination. The Lancet, 396, 1614-1616. https://doi.org/10.1016/S0140-6736(20)32318-7

[51] Venkatasen, M., et al. (2020) Forecasting of the SARS-CoV-2 Epidemic in India Using SIR Model, Fatten Curve and Herd Immunity. Journal of Ambient Intelligence and Humanized Computing, 1-9. https://doi.org/10.1007/s12652-020-02641-4

[52] Shapiro, D., et al. (2007) Yoga as a Complementary Treatment of Depression: Effects of Traits and Moods on Treatment Outcome. Advance Access Publication, 4, 493-502. https://doi.org/10.1093/ecam/nel114

[53] Smith, J.A., Greer, T., Sheets, T. and Watson, S. (2011) Is There More to Yoga than Exercise? Alternative Therapies, 17, 22-29.

[54] Scott, E. (2020) The Benefits of Yoga for Stress Management. https://www.verywellmind.com/the-benefits-of-yoga-for-stress-management-31452 05

[55] Andrew Weil, M.D. (2020) Immunity-Boosting Yoga for Children: 7 Asanas to Build Stronger Immune System. https://www.india.com/health

[56] Doria-Rose, N. and Suthar, M.S. (2021) Antibody Persistence through 6 Months after the Second Dose of mRNA-1273 Vaccine for Covid-19. The New England Journal of Medicine, 384, 2259-2261. http://nejm.org https://doi.org/10.1056/NEJMc2103916

[57] Santino, T.A., et al. (2020) Breathing Exercises for Adults with Asthma. Cochrane Database of Systematic Reviews, No. 3, CD001277. https://doi.org/10.1002/14651858.CD001277.pub4

[58] Saeed, S.Y.A., Antonacci, D.J. and Bloch, R.M. (2010) Exercise, Yoga, and Meditation for Depressive and Anxiety Disorders. American Family Physician, 81, 981-986.

[59] Li, J.G., et al. (2021) Yoga for Secondary Prevention of Coronary Heart Disease: A Systematic Review and Meta-Analysis. Complementary Therapies in Medicine, 57, Article ID: 102643. https://doi.org/10.1016/j.ctim.2020.102643

[60] Kiecolt-Glaser, J.K., et al. (2010) Stress, Inflammation, and Yoga Practice. Psychosomatic Medicine, 72, 113. https://doi.org/10.1097/PSY.0b013e3181cb9377

[61] Sharma, K., Anand, A. and Kumar, R. (2020) The Role of Yoga in Working from Home during the COVID-19 Global Lockdown. Work, 66, 731-737. https://doi.org/10.3233/WOR-203219

[62] Sinclair, D., Purves-Tyson, T.D., Allen, K.M. and Weickert, C.S. (2014) Impacts of Stress and Sex Hormones on Dopamine Neurotransmission in the Adolescent Brain. Psychopharmacology, 231, 1581-1599. https://doi.org/10.1007/s00213-013-3415-Z

[63] Glaser, R. and Kiecolt-Glaser, J. (2014) Stress Damages Immune System and Health. Psychopharmacology, 231, 1581-1599.

[64] Marketon, J.I.W. and Glaser, R. (2008) Stress Hormones and Immune Function. Cellular Immunology, 252, 16-26. https://doi.org/10.1016/j.cellimm.2007.09.006

[65] Raupach, T., Bahr, F., Herrmann, P., Luethje, L., Heusser, K., Hasenfuß, G., Bernar- 
di, L. and Andreas, S. (2008) Slow Breathing Reduces Sympathoexcitation in COPD. European Respiratory Journal, 32, 387-392. https://doi.org/10.1183/09031936.00109607

[66] Russo, M.A., Santarelli, D.M. and O’Rourke, D. (2017) The Physiological Effects of Slow Breathing in the Healthy Human. Breathe, 13, 298-309. https://doi.org/10.1183/20734735.009817

[67] Perciavalle, V., et al. (2016) The Role of Deep Breathing on Stress. Neurological Sciences, 38, 451-458.

[68] Andrew Weil, M.D. (2020) Three Breathing Exercises. http://www.drweil.com/drw/u/ART00521/three-breathing-exercises.html

[69] Bhagat, V., Haque, M. and Jaalam, K. (2017) Breathing Exercise-A Commanding Tool for Self-Help Management during Panic Attacks. Research Journal of Pharmacy and Technology, 10, 4471-4473. https://doi.org/10.5958/0974-360X.2017.00825.3

[70] Joseph, C.N., et al. (2005) Slow Breathing Improves Arterial Baroreflex Sensitivity and Decreases Blood Pressure in Essential Hypertension. Hypertension, 46, 714-718. https://doi.org/10.1161/01.HYP.0000179581.68566.7d

[71] Rucklidge, J.J. and Schofield, G. (2020) Coronavirus and Underlying Medical Conditions: Improving Immunity through Lifestyle Choice. The Conversation.

[72] Bird, S.R. and Hawley, J.A. (2016) Update on the Effects of Physical Activity on Insulin Sensitivity in Humans. BMJ Open Sport \& Exercise Medicine, 2, e000143. https://doi.org/10.1136/bmjsem-2016-000143

[73] Club Industry (2021) Less Physically Active People Have Higher Risk of Severe COVID-19 Outcomes, per Study.

https://www.clubindustry.com/fitness-studies/less-physically-active-people-have-hi gher-risk-severe-covid-19-outcomes-per-study

[74] Berman, R. (2021) Exercise and Mental Health during the COVID-19 Pandemic. https://www.medicalnewstoday.com/articles/exercise-and-mental-health-during-co vid-19-study-explores-link-trends

[75] Marashi, M.Y., Nicholson, E., Ogrodnik, M., Fenesi, B. and Heisz, J. (2021) A Men and Barrier to Health Paradox: Mental Health Was Both a Motivator Physical Activity during the COVID-19 Pandemic. PLOS ONE, 16, e0239244. https://doi.org/10.1371/journal.pone.0239244

[76] Luzi, L. and Radaelli, M.G. (2020) Influenza and Obesity: Its Odd Relationship and the Lessons for COVID-19 Pandemic. Acta Diabetologica, 57, 759-764. https://doi.org/10.1007/s00592-020-01522-8

[77] Morrison, C. (2008) Interaction between Exercise and Leptin in the Treatment of Obesity. Diabetes, 57, 534-535. https://doi.org/10.2337/db08-0007

[78] Vancampfort, D., et al. (2017) Sedentary Behavior and Physical Activity Levels in People with Schizophrenia, Bipolar Disorder and Major Depressive Disorder: A Global Systematic Review and Meta-Analysis. World Psychiatry, 16, 308-315. https://doi.org/10.1002/wps.20458

[79] SaVanna, S. (2021) 9 Ways to Boost Your Body's Natural Defense. https://www.mdseniorresource.org/2020/06/02/9-ways-to-boost-your-bodys-natura 1-defenses

[80] Chastin, S. (2020) Exercise Boosts Immunity and Makes Vaccines More Effective-New Study.

https://www.gavi.org/vaccineswork/exercise-boosts-immunity-and-makes-vaccines- 
more-effective-new-study

[81] WHO (2020) Physical Activity: Staying Active.

[82] Laddu, D.R., Lavie, C.J., Phillips, S.A. and Arena, R. (2020) Physical Activity for Immunity Protection: Inoculating Populations with Healthy Living Medicine in Preparation for the Next Pandemic. Progress in Cardiovascular Diseases, 64, 102-104. https://doi.org/10.1016/j.pcad.2020.04.006

[83] Pedersen, B.K. and Hoffman-Goetz, L. (2000) Exercise, and the Immune System: Regulation Integration and Adaption. Physiological Reviews, 80, 1055-1081. https://doi.org/10.1152/physrev.2000.80.3.1055

[84] Leandro, C.G., Castro, R.M., Nascimento, E., Pithon-Curi, T.C. and Curi, R. (2007) Adaptative Mechanisms of the Immune System in Response to Physical Training. Revista Brasileira de Medicina do Esporte, 13, 343-348. https://doi.org/10.1590/S1517-86922007000500012

[85] Simpson, R.J. and Katsanis, E. (2020) The Immunological Case for Staying Active during the COVID-19 Pandemic. Brain, Behavior, and Immunity, 87, 6-7. https://doi.org/10.1016/j.bbi.2020.04.041

[86] Walsh, N.P., Gleeson, M., Pyne, D.B., et al. (2011) Position Statement Part Two: Maintaining Immune Health. Exercise Immunology Review, 17, 64-103.

[87] Haydon, A.M.M., Maclinnis, R.J., English, D.R. and Giles, G.G. (2005) The Effect of Physical Activity and Body Size on Survival after Diagnosis with Colorectal Cancer. Gut, 55, 62-67.

[88] Lee, I.M. (2003) Physical Activity and Cancer Prevention-Data from Epidemiologic Studies. Medicine \& Science in Sports \& Exercise, 35, 1823-1827. https://doi.org/10.1249/01.MSS.0000093620.27893.23

[89] Nurmasitoh, T. (2015) Physical Activities, Exercises, and Their Effects to the Immune System. Jurnal kedokteran dan kesehatan Indonesia, 7, 52-58. https://doi.org/10.20885/JKKI.Vol7.Iss2.art4

[90] da Silveira, M.P., da Silva Fagundes, K.K., Bizuti, M.R., Starck, É., Rossi, R.C., de Resende, E. and Silva, D.T. (2021) Physical Exercise as a Tool to Help the Immune System against COVID-19: An Integrative Review of the Current Literature. Clinical and Experimental Medicine, 21, 15-28. https://doi.org/10.1007/s10238-020-00650-3

[91] Schijns, V.E. (2001) Activation and Programming of Adaptive Immune Responses by Vaccine Adjuvants.

[92] Goldsby, R., Kindt, T.J., Osborne, B.A. and Kuby, J. (2003) Chapter 2: Cells and Organs of the Immune System. In: Freeman, W.H., Ed., Immunology, 5th Edition, New York, 24-56.

[93] (2021) 5 Ways to Boost Your Immunity without Any Supplements. https://imesofindia.indiatimes.com/life-style/health-fitness/health-news/5-ways-toboost-your-immunity-without-anysupplements/photostory/82769589.cms

[94] Calder, P.C. and Jackson, A.A. (2000) Undernutrition, Infection and Immune Function. Nutrition Research Reviews, 13, 3-29.

https://doi.org/10.1079/095442200108728981

[95] Sekhon, H.K. and Kaur, G. (2014) Sex Hormone and Immune Dimorphism. The Scientific World Journal, 2014, Article ID: 159150.

https://doi.org/10.1155/2014/159150

[96] American Cancer Society (2019) Immunotherapy, Cytokines and Their Side Effects.

[97] Ahmed, S.A. and Penhale, W.J. (1982) The Influence of Testosterone on the Devel- 
opment of Autoimmune Thyroiditis in Thymectomized and Irradiated Rats. Clinical \& Experimental Immunology, 48, 367-374.

[98] Mandal, A. (2019) Hormones and Where Do Hormones Release from. News Medical: Life Sciences, November.

[99] Mandal, A. (2019) Effects of Hormone. News Medical: Life Sciences, November.

[100] Breuning, L.G. (2012) Meet Your Happy Chemicals: Dopamine, Endorphin, Oxytocin. Serotonin-Inner Mammal Institute.

[101] Mandal, A. (2019) What Are Hormones? https://www.news-medical.net/health/What-are-Hormones.aspx

[102] Jacob, C., Litorco, J. and Lee, L. (2004) Immunity through Swarms: Agent-Based Simulations of the Human Immune System. International Conference on Artificial Immune Systems (ICARIS), Catania, 13-16 September 2004, 400-412. https://doi.org/10.1007/978-3-540-30220-9_32

[103] Clark, W.R. (2007) In Defense of Self How the Immune System Really Works. Oxford University Press, Oxford.

[104] Stocchi, V., De Feo, P. and Hood, D.A. (2007) Role of Physical Exercise in Preventing Disease and Improving the Quality of Life, Springer-Verlag Mailand.

[105] Simpson, R.J., Campbell, J.P., Gleeson, M., Kruger, K., Nieman, D.C., Pyne, D.B., Turner, J.E. and Walsh, N.P. (2020) Can Exercise Affect Immune Function to Increase Susceptibility to Infection? Exercise Immunology Review, 26, 8-22.

[106] da Silveira, M.P., et al. (2021) Physical Exercise as a Tool to Help the Immune System against COVID-19: An Integrative Review of the Current Literature. Clinical and Experimental Medicine, 21, 15-28. https://doi.org/10.1007/s10238-020-00650-3

[107] WHO (2020) Impact of Physical Activity on Health.

[108] ISU Study: Moderate Exercise in Mice Boosts Immune System, Diminishes Flu's Severity. https://www.news.iastate.edu/news/2009/oct/exercise

[109] Berman, R. (2020) Exercise and Mental Health during the COVID-19 Pandemic. https://www.medicalnewstoday.com/articles/exercise-and-mental-health-during-co vid-19-study-explores-link-trends

[110] Archer, T. and Garcia, D. (2015) Exercise and Dietary Restriction for Promotion of Neurohealth Benefits. Health, 7, 136-152. https://doi.org/10.4236/health.2015.71016

[111] Nagendra, H.R. (2020) Yoga for COVID-19. International Journal of Yoga, 13, 87-88. https://doi.org/10.4103/ijoy.IJOY_27_20

[112] Russo, M.A., Santarelli, D.M. and O’Rourke, D. (2017) The Physiological Effects of Slow Breathing in the Healthy Human. Breathe, 13, 298-309.

https://doi.org/10.1183/20734735.009817

[113] Brennan, D. (2021) What Foods Are Highest in Vitamin D? https://www.medicinenet.com/what_foods_are_highest_in_vitamin_d/article.htm

[114] Lee, G.Y. and Han, S.N. (2018) The Role of Vitamin E in Immunity. Nutrients, 10, 1614. https://doi.org/10.3390/nu10111614

[115] Kamrujjaman, M., Mahmud, M.S. and Islam, M.S. (2021) Dynamics of a Diffusive Vaccination Model with Therapeutic Impact and Non-Linear Incidence in Epidemiology. Journal of Biological Dynamics, 15, S105-S133.

https://doi.org/10.1080/17513758.2020.1849831

[116] Mahmud, M.S., Kamrujjaman, M. and Islam, M.S. (2019) A Spatially Dependent Vaccination Model with Therapeutic Impact and Non-Linear Incidence. In: Mishra, S.R., Dhamala, T.N., Makinde, O.D., Eds., Recent Trends in Applied Mathematics. 
Lecture Notes in Mechanical Engineering, Springer, Singapore. https://doi.org/10.1007/978-981-15-9817-3_22

[117] Hansen, M.D. (2010) How Exercise Benefits the Immune System.

[118] (2021, February 3) Everything You Need to Know about Herd Immunity and the Dangers Associated with It. Times of India.

[119] (2021, January 23) Health Essentials: The Short Answer from an Immunity and Pulmonary Medicine Physician.

[120] (2021) Triple mutation Covid variant in India? https://timesofindia.indiatimes.com/india/triple-mutation-covid-variant-in-india-h eres-what-we-know-so-far/articleshow/82183386.cms

[121] Cherian, S., et al. (2021) Convergent Evolution of SARS-CoV-2 Spike Mutations, L452R, E484Q and P681R, in the Second Wave of COVID-19 in Maharashtra, India. NIC Team. https://doi.org/10.1101/2021.04.22.440932

[122] Hoffmann, M., et al. (2021) SARS-CoV-2 Variant B.1.617 Is Resistant to Bamlanivimab and Evades Antibodies Induced by Infection and Vaccination. https://doi.org/10.1101/2021.05.04.442663

[123] Yadav, P.D., et al. (2021) SARS CoV-2 Variant B.1.617.1 Is Highly Pathogenic in Hamsters than B.1 Variant. https://doi.org/10.1101/2021.05.05.442760

[124] Yadav, P., et al. (2021) Neutralization of Variant under Investigation B 1.617 with Sera of BBV152 Vaccines. https://doi.org/10.1101/2021.04.23.441101 